\title{
Structural, Optical and Electrical Conductivity Studies in Polycarbazole and Its Metal Oxide Nano Composites
}

Sankarappa Talari ( $\sim$ sankarappa@rediffmail.com )

Gulbarga University

B. Raghavendra

Gulbarga University

Amarkumar Malge

Gulbarga University

\section{Research Article}

Keywords: Polycarbozole, poymer nano composites, conductivity, optical absorption, band gap

Posted Date: October 26th, 2021

DOl: https://doi.org/10.21203/rs.3.rs-993638/v1

License: (c) (i) This work is licensed under a Creative Commons Attribution 4.0 International License.

Read Full License 


\section{Abstract}

Polycarbazole (PCz) has been synthesized by chemical oxidation method using APS as an oxidizing agent and $\mathrm{PCz} / \mathrm{CuO}$ and $\mathrm{PCz} / \mathrm{Fe}_{2} \mathrm{O}_{3}$ nanocomposites by in situ polymerization method for different wt\% of $\mathrm{CuO}$ and $\mathrm{Fe}_{2} \mathrm{O}_{3}$ at room temperature. XRD patterns confirmed crystalline nature of samples. FTIR indicated strong interaction between PCz and nano fillers. The morphological and optical absorption studies were carried out using SEM and UV-Vis respectively. Addition of $\mathrm{CuO}$ or $\mathrm{Fe}_{2} \mathrm{O}_{3}$ to PCz decreased its direct and indirect band gaps. However, band gap showed a small change with dopant contents up to $30 \%$. Urbach energy decreased with the addition of dopants. But Urbach energy of the composites increased with increasing dopants content from 10 to $30 \%$. DC conductivity of PCz and its nanocomposites has been measured by following two probe technique in the temperature range from $300 \mathrm{~K}$ to $423 \mathrm{~K}$. he conductivity of both the nanocomposites is found to be less than the pure PCz and it is found to increase with wt\% of $\mathrm{CuO}$ or $\mathrm{Fe}_{2} \mathrm{O}_{3}$ as the case may be. The activation energy has been determined by fitting Arrhenius expression to the dc conductivity data at high temperature. The activation energy of polycarbazole is determined to be less than that of the composites. In both the composites, activation energy decreased and conductivity increased with the increase of dopant content.

\section{Introduction}

Polymers are the outstanding invention of the twentieth century which are of long chain structure and generally shows insulating behavior. Conducting polymers are a group of polymers which conduct electricity in pure and doped forms. Conducting polymers are extensively used in manufacturing of sensors, solar cells, diodes, electrochemical super capacitors, memory storage devices, actuators and corrosion protection [1-7].

Recently, the conductivity of many conducting polymers doped with metal oxides have been widely investigated. Among these, polycarbazole (PCz) has been captivated more by its superior properties such as good electrical and thermal, conductivity, high hole mobility, low redox potential and feasible molecular structure and tuning properties [8]. Ahmad Zahoor et al [9] have fabricated Ag/PCz by microwave polyyol reduction method. Through FTIR and Raman measurements they observed that Ag nanoparticles are enclosed by 3,6 polycarbazole. It was concluded that these composites are advantageous to combine the luminescence behavior of Ag nanopartiles and PCz. Umair Baig et al [10], studied DC conductivity of $\mathrm{PCz} / \mathrm{ZrP}$ and reported increase in resistivity on exposure to ammonia, at room temperature. Aditi Srivatsva et al [11] have fabricated a p-Polycarbazole/n-ZnO hybrid heterojunction diode and reported that it exhibits low dark current in the range of $10^{-11} \mathrm{~A}$.

The electrical and optical properties of a conducting polymer could be altered by doping metal oxides to it. There have been many studies reported on metal oxide doped polymer nanocomposites with dopants such as $\mathrm{CuO}, \mathrm{ZnO}, \mathrm{Cu}_{2} \mathrm{O}, \mathrm{MnO}_{2}, \mathrm{ZrO}_{2}, \mathrm{TiO}_{2}$ and $\mathrm{SnO}_{2}$ [12-18]. Copper Oxide is blackish brown in color and has monoclinic structure. The manufacturing cost of $\mathrm{CuO}$ is vary less, shows semiconducting nature and 
measure a small band gap. S. Ashokan et al [19] have studied conducting properties and sensing properties of PANI/CuO nanocomposites. G. Rajasudha et at [20] have synthesized polyindole-CuO nanocomposite by sol gel method and studied temperature dependent conductivity of polyindole/CuO nanocomposite. Polypyrrole-CuO nano composites were prepared by khan Malook et al. They observed that the incorporation of different concentration of $\mathrm{CuO}$ to polypyrrole decreases the energy band gap of polypyrrole [21]. $\mathrm{Fe}_{2} \mathrm{O}_{3}$ is an inorganic n-type semiconductor shows a nontoxic behavior, which can be abundantly obtained in nature. $\mathrm{Fe}_{2} \mathrm{O}_{3}$ is considered as a good electrode material used for constructing lithium ion batteries. R. Gangopadhyaya et al [22] have prepared polypyrrole/ $\mathrm{Fe}_{2} \mathrm{O}_{3}$ naocomposites and studied conductivity. They noted variations in both ac and dc conductivity for different concentration of $\mathrm{Fe}_{2} \mathrm{O}_{3}$.

In view of the fact that there are no many reports on PCz and its composites, we synthesized and investigated polycarbazole, $\mathrm{PCz} / \mathrm{CuO}$ and $\mathrm{PCz} / \mathrm{Fe}_{2} \mathrm{O}_{3}$ nanocomposites for structural, morphological, optical and electrical properties. Results have been analyzed and presented in this article.

\section{Experimental}

\subsection{SAMPLE PREPARATION}

The materials used are carbazole (Sigma-Aldrch), acetonitrile (SD-Fine), Ammonium persulfate, (SD fine), Acetone (Merck), $\mathrm{CuO}$ (HIMEDIA), $\mathrm{Fe}_{2} \mathrm{O}_{3}$ (HIMEDIA), nanoparticles and deionised water are of analytical grade.

\section{SYNTHESIS OF PCZ}

The PCz was synthesized by chemical oxidative polymerization method. Monomer solution was prepared by dissolving $3.34 \mathrm{gm}$ of Carbazole in $50 \mathrm{ml}$ of acetonitrile. The APS (oxidant) solution was prepared by dissolving $9.12 \mathrm{gms}$ of APS in $50 \mathrm{ml}$ of water. Molar ratio of 1:2 was maintained between monomer and oxidant. The APS solution was added slowly (drop wise) to the carbazole solution over a period of 30 min. The mixture was constantly stirred for 24 hours at room temperature and obtained dark green solution. The precipitate was filtered and washed several times with deionised water and methonal and kept the yield for annealing at $150 \mathrm{C}$.

\section{SYNTHESIS OF PCZ/CuO AND PCZ/Fe $\mathrm{O}_{3}$ COMPOSITES}

The nanocomposites were prepared by in situ oxidative polymerization of carbazole by adding different amounts of CuO using APS as oxidizing agent. Carbazole (3.34gms) was dissolved in acetonitrile (50ml). $\mathrm{CuO}(10 \mathrm{wt} \%)$ nanoparticles was added to monomer solution under vigorous stirring. APS solution (9.12gms in $50 \mathrm{ml}$ of water) was added drop wise to the above solution over a period of 15 minutes. The entire solution was stirred for 24 and the color of the solution turned to dark green. The precipitate was washed several times with deionised water and methanol successively, filtered and then dried. $\mathrm{PCz} / \mathrm{Fe}_{2} \mathrm{O}_{3}$ 
nanocomposites of different wt\% of $\mathrm{Fe}_{2} \mathrm{O}_{3}$ were synthesized by following the same procedure. The different concentrations of $\mathrm{CuO}$ and $\mathrm{Fe}_{2} \mathrm{O}_{3}(10,20,30$ wt\%) were prepared and labeled as PCu10, PCu20, PCu30 and PFO10, PFO20 and PFO30 respectively.

\subsection{MEASUREMENTS}

The powder XRD experiments were performed on all the samples using Cu-Ka radiation of wavelength $1.5405 \AA$ in a Rigaku Ultima IV diffractometer. SHIMADZUIR-Prestige-21 Fourier transform infrared spectrophotometer was used to acquire FTIR spectra of the samples in the wave number range of $400-$ $4000 \mathrm{~cm}^{-1}$. UV-Visible spectra were recorded using UV Visible1899 spectrometer for the wavelength range $200-900 \mathrm{~nm}$. The samples which are in powder form were pelletized in a hydraulic press by applying the pressure of $20 \mathrm{~kg} / \mathrm{cm}^{2}$. The dc conductivity measurements were carried out by applying a constant voltage of $5 \mathrm{~V}$ across the pellet in the temperature range from $300 \mathrm{~K}$ to $423 \mathrm{~K}$ by employing a two probe method. Current was measured using a nano ammeter. The electrical resistivity, $\rho$ was estimated by $\rho=R(A / t)$, where $R=(V / I)$, $A$ is area of cross section and $t$ the thickness of pellet. Conductivity, $\sigma$ has been determined using the expression, $\sigma=1 / \rho$, within the accuracy of $2 \%$.

\section{Results And Discussion}

\subsection{XRD}

The crystalline structure of pure $\mathrm{PCz}$ and composites $\mathrm{PCz} / \mathrm{CuO}$ and $\mathrm{PCz} / \mathrm{Fe}_{2} \mathrm{O}_{3}$ were investigated from XRD patterns. The XRD patterns of the present samples are shown in the below Fig. 1. Some diffraction peaks corresponding to different crystalline planes can be seen. The sharp peaks at $35.77,38.91,48.82$, 53.54, 58.54, 61.62, 66.50, 68.18, 72.59, 75.35 correspond to (0 0 2), (2 0 0), (2 0 2), (0 20 ), (2 0 2), (1 1

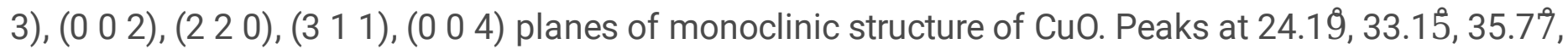

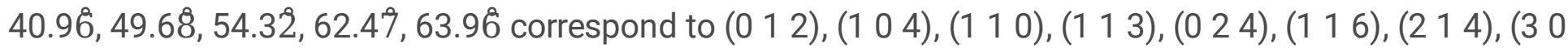
0) planes of rhombohedral structure of $\mathrm{Fe}_{2} \mathrm{O}_{3}$. The $\mathrm{CuO}$ and $\mathrm{Fe}_{2} \mathrm{O}_{3}$ patterns are found to be consistent with JCPDS file Nos. 48-1548 and 89-8104 respectively [19, 23]. The peaks at 19.03, 20.01, 21.16, 23.16, 28.12 correspond the planes (2 0 -1), (1 2 -1), (2 20$)$, ( $\left.\begin{array}{lll}0 & 1 & 2\end{array}\right),\left(\begin{array}{lll}2 & 1 & 0\end{array}\right)$ of polycarbazole [24]. The increase in peak intensity with increasing concentration of $\mathrm{CuO}$ and $\mathrm{Fe}_{2} \mathrm{O}_{3}$ confirms interaction of dopants with $\mathrm{PCz}$. The crystallinity of the composites enhanced due to increased concentration of nano sized dopants.

The crystallite size, D was determined from XRD patterns using Debye Scherer's formula showed in Eqn (1) and micro strain, $\varepsilon$ using Eqn (2) [25],

$$
\begin{aligned}
& \mathrm{D}=\frac{K \lambda}{\beta \operatorname{Cos} \theta}(1) \\
& \varepsilon=\frac{\beta}{4 \tan \theta}(2)
\end{aligned}
$$


Where, $\mathrm{K}$ is a constant called shape factor equal to 0.9 for spherical shaped particles [24], $\lambda$ is wavelength of X-ray $(\nabla 1.5406 \AA), B$ is full width half maximum and $\theta$ position of the peak. The prominent peak for each sample was considered for determining crystallite size and micro strain. The obtained values of crystallite size, average crystallite size and micro strain of the samples are tabulated in Table 1. It can observed that the crystallite size of PCz is less compared to composites, crystallite size is increasing and micro strain is decreasing with wt\% of dopants which confirms encapsulation of polycarbazole on the dopant particles. These are in qualitative agreement with the literature on $\mathrm{PCz} / \mathrm{SnO}_{2}$ [24].

Table 1

Crystallite size, D average crystallite size and Micro strain, $\varepsilon$ of PCz, PCuO and PFO composites.

\begin{tabular}{|c|c|c|c|c|c|c|}
\hline $\begin{array}{l}\text { SI } \\
\text { no }\end{array}$ & Sample & $\begin{array}{l}2 \theta \\
\text { (Degrees) }\end{array}$ & $\begin{array}{l}\text { FWHM } \\
\text { (B) }\end{array}$ & $\begin{array}{l}\text { Crystallite } \\
\text { size } \\
(\mathrm{nm})\end{array}$ & $\begin{array}{l}\text { Average crystallite } \\
\text { size } \\
(\mathrm{nm})\end{array}$ & $\begin{array}{l}\text { Micro strain } \\
(\varepsilon)\end{array}$ \\
\hline 1 & $\mathrm{PCz}$ & 20.04 & 0.33 & 24.07 & 24.07 & 0.47 \\
\hline 2 & CuO & 35.60 & 0.27 & 29.42 & 29.42 & \\
\hline 3 & $\mathrm{Fe}_{2} \mathrm{O}_{3}$ & 33.35 & 0.31 & 25.62 & 25.62 & \\
\hline 4 & PCu10 & 19.43 & 0.30 & 26.51 & 34.14 & 0.44 \\
\hline 5 & PCu20 & 19.53 & 0.25 & 31.77 & & 0.36 \\
\hline 6 & PCu30 & 19.52 & 0.18 & 44.15 & & 0.26 \\
\hline 7 & PF010 & 19.49 & 0.26 & 30.06 & 42.89 & 0.38 \\
\hline 8 & PFO20 & 19.51 & 0.19 & 41.81 & & 0.27 \\
\hline 9 & PF030 & 19.47 & 0.14 & 56.82 & & 0.20 \\
\hline
\end{tabular}

\subsection{FTIR ANALYSIS}

The FTIR has been analyzed to know different functional groups developed in the composites due to interaction between constituents such as $\mathrm{PCz}$ and $\mathrm{CuO}$ and, $\mathrm{PCz}$ and $\mathrm{Fe}_{2} \mathrm{O}_{3}$. The spectra of the present nanocomposites are shown in the Fig. 2. The IR bands at $726 \mathrm{~cm}^{-1}$ and $812 \mathrm{~cm}^{-1}$ are due to $\mathrm{C}-\mathrm{H}$ deformation of di-substituted and tri-substituted benzene ring of $\mathrm{PCz}$ respectively [26, 27]. A sharp band around $3415 \mathrm{~cm}^{-1}$ refers to stretching of the $\mathrm{N}-\mathrm{H}$ bond in $\mathrm{PCz}$. The change in intensity and shifting of $3415 \mathrm{~cm}^{-1}$ band evidenced the formation of bond between $\mathrm{NH}$ group of $\mathrm{PCz}$ and $\mathrm{CuO}$ and, $\mathrm{Fe}_{2} \mathrm{O}_{3}$ [25]. The presence of the stretching band at $1227 \mathrm{~cm}^{-1}$ is attributed to $\mathrm{C}=\mathrm{N}$ and the peak at $1316 \mathrm{~cm}^{-1}$ is attributed to $\mathrm{C}-\mathrm{H}$ out of plane bending vibration of aromatic ring. The sharp band at $1444 \mathrm{~cm}^{-1}$ may be due to ring stretching vibration of carbazole [27]. The bands at $918 \mathrm{~cm}^{-1}$ and $1598 \mathrm{~cm}^{-1}$ are assigned to $=\mathrm{CH}$ out of plane and stretching mode of aromatic alkene respectively [21, 25]. A strong absorption band at $562 \mathrm{~cm}^{-1}$ 
and at $602 \mathrm{~cm}^{-1}$ in the composites confirms incorporation of $\mathrm{Cu}-\mathrm{O}$ and $\mathrm{Fe}-\mathrm{O}$ vibrational modes respectively [21,23]. The assignment of bands of different fuctional groups are tabulated in Table 2 .

Table 2

Assignment of bands to different functional groups in FTIR spectra of PCz, PCuo and PFO composites.

\begin{tabular}{|c|c|c|c|c|}
\hline S.No & $\begin{array}{l}\text { FTIR bands } \\
\text { in } \mathrm{PCZ} \\
\left(\mathrm{cm}^{-1}\right)\end{array}$ & $\begin{array}{l}\text { FTIR bands in } \\
\text { PCz/CuO } \\
\text { composites }\left(\mathrm{cm}^{-1}\right)\end{array}$ & $\begin{array}{l}\text { FTIR bands in } \\
\mathrm{PCZ} / \mathrm{Fe}_{2} \mathrm{O}_{3} \\
\text { composites }\left(\mathrm{cm}^{-1}\right)\end{array}$ & Assignment of bands \\
\hline 1 & & & $562-563$ & $\begin{array}{l}\text { Fe-0 stretching vibratio } \\
\text { mode[23] }\end{array}$ \\
\hline 2 & & 602 To 610 & & Vibration of Cu-O bond[21] \\
\hline 3 & 726 & 717 To 723 & 720 & $\begin{array}{l}\text { Ring deformation of } \\
\text { substituted aromatic } \\
\text { structure[26] }\end{array}$ \\
\hline 4 & 812 & 812 & 814 & $\begin{array}{l}\mathrm{C}-\mathrm{H} \text { deformation in tri } \\
\text { substituted benzene } \\
\text { ring[27] }\end{array}$ \\
\hline 5 & 918 & 918 & 918 & $\begin{array}{l}=\mathrm{CH} \text { out of plane } \\
\text { vibrations[21] }\end{array}$ \\
\hline 6 & 1227 & 1227 & 1232 & $\mathrm{C}=\mathrm{N}$ stretching[27] \\
\hline 7 & 1316 & 1316 & 1316 & $\begin{array}{l}\text { C-H out of plane bending } \\
\text { vibration of aromatic } \\
\text { ring[27]. }\end{array}$ \\
\hline 8 & 1444 & 1444 & 1444 & $\begin{array}{l}\text { Ring stretching vibration of } \\
\text { carbazole moiety[27]. }\end{array}$ \\
\hline 9 & 1598 & 1598 & 1598 & $\begin{array}{l}\text { stretching mode of } \\
\text { aromatic alkene [25] }\end{array}$ \\
\hline 10 & 3415 & $3415-3419$ & $3415-3420$ & Stretching of $\mathrm{N}-\mathrm{H}$ bond [25] \\
\hline
\end{tabular}

\subsection{MORPHOLOGY}

Figure 3 show3.3 MORPHOLOGYs typical SEM images of PCz, PCu10 and PFO10 nanocomposites. It is evident from the images that the polycarbazole has homogeneous surface morphology with nodular nature and the particles are agglomerate. It can be observed from the images of the $\mathrm{PCz} / \mathrm{CuO}, \mathrm{PCz} / \mathrm{Fe}_{2} \mathrm{O}_{3}$ nanocomposites the morphological changes occurring upon adding the $\mathrm{CuO} / \mathrm{Fe}_{2} \mathrm{O}_{3}$ nanoparticles. The added nanofillers lead to branching of polymer chain in the polycarbazole and that intern create network like structure in composites, Polycarbazole in PFO composites.

\subsection{UV-VIS ABSORPTION ANALYSIS}


Figure 4 (a \& b) depicts optical absorption spectra of the samples PCz, PCu10, PCu20, PCu30, PF010, PFO20 and PFO30. A broad band is observed at $279 \mathrm{~nm}$ in pure polycarbazole is assigned to bonding and antibonding $\left(\pi-\pi^{*}\right)$ transition of the benzoid ring and small peak around $347 \mathrm{~nm}$ is corresponding to polaronic energy level $\left(n-\pi^{\star}\right)$ transition of the quinoid ring. The polaronic energy level is created by the formation of defects during polymerization process $[24,26]$. It is observed that the peaks are slightly shifted to blue end about $4 \mathrm{~nm}$ for $\mathrm{CuO}$ composites and to $8 \mathrm{~nm}$ for $\mathrm{Fe}_{2} \mathrm{O}_{3}$ composites of spectrum and also there is variation in the intensity with different concentration of $\mathrm{CuO}$ and $\mathrm{Fe}_{2} \mathrm{O}_{3}$. This is because $\mathrm{CuO}$ or $\mathrm{Fe}_{2} \mathrm{O}_{3}$ nanoparticles absorbs partly incident radiation by their free electrons and due to the strong interaction between polymer and dopant nanopartiles. The blue shift on a small scale with increase in $\mathrm{CuO}$ wt\% is in agreement with the reports, $\mathrm{PCz} / \mathrm{SnO}_{2}$ [25].

The optical absorption gives information about band gap and electronic transitions. Optical energy gaps can be determined using Mott-Davis-Tauc's equation [28].

$(\mathrm{ahv})^{1 / \mathrm{n}}=\frac{2.303}{d}=\mathrm{B}\left(\mathrm{hv}-\mathrm{E}_{\mathrm{g}}\right)$

Where, $\mathrm{a}$ is the absorption coefficient, $\mathrm{B}$ the absorption constant, $h v$ the energy of the photon, $\mathrm{E}_{\mathrm{g}}$ the optical energy gap and $d$ the sample thickness. The exponent $(1 / n)$ represents different electronic transitions and it takes values $\frac{1}{2}, 2, \frac{3}{2}$ and 3 corresponding to allowed direct, indirect, forbidden direct and forbidden indirect transitions respectively. The direct and indirect energy gaps are determined from the transition of electrons from valance band to conduction band when photons interact with them in the valance band.

The Tauc's plots for direct and indirect transitions were made and tangents to the band edges were extrapolated on to the $h v$-axis. The intersecting values on $h v$-axis gave band gap values corresponding to direct or indirect transitions as the case may be. The typical plots of direct band gap for one sample in each series and for pure PCz are shown in Fig. 5 and for indirect band gap in Fig. 6. To save space, Tauc's plots for all the corresponding are not shown in the Fig. 5 \& 6 .

The results tabulated in Table 3 revealed that the intended direct and indirect band gap values of pure $\mathrm{PCz}$ were $3.32 \mathrm{eV}$ and $3.42 \mathrm{eV}$ respectively. For PCu10, direct and indirect gaps are found to be $3.47 \mathrm{eV}$ and $3.54 \mathrm{eV}$ respectively. It implies that band gap values increases on doping PCz with CuO. Similarly, for PF010, direct and indirect gaps are $3.49 \mathrm{eV}$ and $3.53 \mathrm{eV}$. These results are also suggest that band gap of $\mathrm{PCz}$ increases when doped with $\mathrm{Fe}_{2} \mathrm{O}_{3}$. This may be due to strong interaction between the polymer matrix and dopant oxides. Increase of $\mathrm{CuO}$ or $\mathrm{Fe}_{2} \mathrm{O}_{3}$ from $10 \mathrm{wt} \%$ to $30 \mathrm{wt} \%$ decreases band gaps slightly. Similar nature of results were reported for $\mathrm{PCz} / \mathrm{SnO}_{2}$ and $\mathrm{PVA} / \mathrm{CuO}[24,28]$. 
Table 3

Optical Band gap energy (direct and indirect) and Urbach energy values for PCz, PCuo and PFO composites.

\begin{tabular}{|lllll|}
\hline SI no & Sample & $\begin{array}{l}\text { Direct band gap } \\
\mathrm{E}_{\mathbf{g}}(\mathrm{eV})\end{array}$ & $\begin{array}{l}\text { Indirect band gap } \\
\mathrm{E}_{\mathbf{g}}(\mathrm{eV})\end{array}$ & $\begin{array}{l}\text { Urbach energy } \\
\mathrm{E}_{\mathbf{u}}(\mathrm{eV})\end{array}$ \\
\hline 1 & PURE PCz & 3.32 & 3.42 & 0.32 \\
\hline 2 & PCu10 & 3.47 & 3.54 & 0.30 \\
\hline 3 & PCu20 & 3.48 & 3.53 & 0.31 \\
\hline 4 & PCu30 & 3.46 & 3.52 & 0.32 \\
\hline 5 & PFO10 & 3.49 & 3.53 & 0.30 \\
\hline 6 & PFO20 & 3.47 & 3.52 & 0.32 \\
\hline 7 & PFO30 & 3.46 & 3.51 & 0.33 \\
\hline
\end{tabular}

The Urbach energy $\left(E_{u}\right)$ was determined by plotting $\ln (\mathrm{a})$ versus $h v$ as depicted in Fig. 7. Urbach energy $\left(E_{u}\right)$ of pure $P C z$ is determined to be $0.325 \mathrm{eV}$ [Table 3]. This value decreased to $0.307 \mathrm{eV}$ when $10 \mathrm{wt} \%$ of $\mathrm{CuO}$ or $\mathrm{Fe}_{2} \mathrm{O}_{3}$ are doped to PCz. Since Urbach energy is a measure of defects in the sample, present results indicate that samples improve their quality in terms of defects when they were doped with $10 \mathrm{wt} \%$ of dopant oxides. On increasing dopants beyond $10 \mathrm{wt} \%$ Urbach energy increases. This reveals that higher amounts of dopant oxides increases concentration of structural defects in the samples. Similar results were quoted for PVA/CuO composits [28].

\subsection{CONDUCTIVITY}

Conductivity, $\sigma$ of pure $\mathrm{PCz}$ and the composites is observed to be increasing with increase of temperature and is of the order of $10^{-5}(\Omega \mathrm{m})^{-1}$. This reveals semiconducting behavior of the samples. In composites, conductivity increased with increase of $\mathrm{CuO}$ or $\mathrm{Fe}_{2} \mathrm{O}_{3}$ contents. Conductivity of the composites is found to be less than that of pure $\mathrm{PCz}$ at all the temperatures of interest. Increase in conductivity with increase in $\mathrm{CuO} / \mathrm{Fe}_{2} \mathrm{O}_{3}$ concentration may be due to formation of well organized network for transportation of charge carriers by the added dopants. Raj et al studied temperature dependent conductivity of pure PCz and their conductivity was in the order of $10^{-5}(\Omega \mathrm{m})^{-1}[26]$.

The temperature variation of electrical conductivity is analyzed using Arrhenius expression,

$\sigma=\sigma_{0} \exp \left(E_{a} / k_{B} T\right)(4)$

Where, $\sigma$ is conductivity, $E_{a}$ the activation energy and $k_{B}$ the Boltzman constant. 
Figure 8 and Fig. 9 shows the plots of $\ln (\sigma)$ versus $(1 / T)$ for pure PCz and PCuO and PFO composites respectively. The linear lines were fit to the data at higher temperatures and the obtained slopes of the fits were used to determine the activation energy $E_{a}$. Fig. 10 shows activation energy $\left(E_{a}\right)$ and $\sigma$ at $400 \mathrm{~K}$ versus wt\% of $\mathrm{CuO} / \mathrm{Fe}_{2} \mathrm{O}_{3}$ composites, it can be seen that activation energy $\mathrm{E}_{\mathrm{a}}$ decreased and conductivity increased with increase of dopant concentration and, it may be due to the decrease in the scattering rate of polarons with increase of $\mathrm{CuO} / \mathrm{Fe}_{2} \mathrm{O}_{3}$ concentration. The conductivity and activation energy values of $\mathrm{PCz}, \mathrm{PCz} / \mathrm{CuO}$ and $\mathrm{PCz} / \mathrm{Fe}_{2} \mathrm{O}_{3}$ nanocomposites at $350 \mathrm{~K}$ and $400 \mathrm{~K}$ are tabulated in Table 4. To emphasize conductivity behavior with filler content its value at two different temperatures are shown in Table 4. Similar kind of behavior in $\mathrm{E}_{\mathrm{a}}$ and $\sigma$ has been observed by J. Selvi et al [29] for PVA/CuO composites and noticed enhancement in conductivity and reduced activation energy in PVA doped CuO. Mohammad Shakir et al [30] have noticed increase in conductivity with $\mathrm{TiO}_{2}$ content in $\mathrm{PCz} / \mathrm{TiO}_{2}$ nanocomposite. Syed Abthagir et al [31] compared conductivity of polyindole, polycarbazole and their derivatives and found that polycarbazole had higher conductivity than polyindole.

Table 4

DC conductivity, $\sigma$ at $350 \mathrm{~K}$ and $400 \mathrm{~K}$ and activation energy, $\mathrm{E}_{\mathrm{a}}$ for conduction for PCz and PCuO and PFO composites .

\begin{tabular}{|c|c|c|c|c|}
\hline sl no & Sample & $\begin{array}{l}E_{a} \\
(m e V)\end{array}$ & $\begin{array}{l}\sigma(350 \mathrm{~K}) \\
\left(\times 10^{-5}\right)(\Omega \mathrm{m})^{-1}\end{array}$ & $\begin{array}{l}\sigma(400 \mathrm{~K}) \\
\left(\times 10^{-5}\right)(\Omega \mathrm{m})^{-1}\end{array}$ \\
\hline 1 & PCz & 4.91 & 3.19 & 3.26 \\
\hline 2 & PCu10 & 15.11 & 1.95 & 2.07 \\
\hline 3 & PCu20 & 8.29 & 2.07 & 2.13 \\
\hline 4 & PCu30 & 7.25 & 2.45 & 2.55 \\
\hline 5 & PF010 & 8.68 & 1.20 & 1.25 \\
\hline 6 & PF020 & 8.42 & 1.80 & 1.83 \\
\hline 7 & PF030 & 5.99 & 2.22 & 2.27 \\
\hline
\end{tabular}

\section{Conclusions}

In the present work, polycarbazole has been synthesized via chemical oxidation method and the composites, $\mathrm{PCz} / \mathrm{CuO}$ and $\mathrm{PCz} / \mathrm{Fe}_{2} \mathrm{O}_{3}$ by in situ polymerization technique. The samples were characterized by XRD, FITR, SEM and UV-Vis. The results revealed that the composites are influenced by the loaded $\mathrm{CuO} / \mathrm{Fe}_{2} \mathrm{O}_{3}$ nanofillers. Crystalline nature of the materials and strong interaction between PCz and dopants are confirmed by XRD and FTIR respectively. SEM images showed a remarkable morphological distinction between the polycarbazole and the composites. The optical absorption bands showed blue shifts in the peak positions which reveals inter molecular interactions between the added nanofillers and the polymer matrix. The direct and indirect band gaps were determined by Mott-Davis 
Tauc equation and found that the band gap of the composites are higher than the pure polycarbazole and the band gaps of the composites showed a small change with dopant content up to wt $30 \%$ with increase in wt\% of the fillers. Conductivity of both PCz and the composites increased with increase in temperature indicating semiconducting nature. conductivity of the composites increased and activation decreased with wt\% of $\mathrm{CuO} / \mathrm{Fe}_{2} \mathrm{O}_{3}$ content. For the first time $\mathrm{PCz}$ and its metal oxides doped composites have been thoroughly investigated for structural, morphological, optical and electrical conductivity.

\section{References}

1. M.C. Santos, O.H.C. Hamdan, S.A. Valverde, E.M. Bianchi, Synthesis and characterization of $\mathrm{V}_{2} \mathrm{O}_{5}$ /PANI thin films for application in amperometric ammonia gas senors, 65, (2019) 116-120, https://doi.org/10.1016/j.orgel.2018.11.013

2. K.M. Zaidan, H.F. Hussein, R.A. Hassan, Synthesis and characterization of (Pani/n-si) solar cell. Energy procedia 6, 85-91 (2011). https://doi.org/10.1016/j.egypro.2011.05.010

3. M. Gokcen, T. Tunc, S. Altindal, I. Uslu, Electrical and photocurrent characteristics of Au/PVA (Codoped)/n-Si Photoconductive diodes, Materials Science and Engineering:B 177, 5, (2012) 416-420, https://doi.org/10.1016/j.mseb.2012.01.004

4. B. Muthulakshmi, D. Kalpana, S. Pitchumani, N.G. Renganathan, Electrochemical deposition of polypyrrole for symmetric supercapacitors, Journal of power sources, 158, 2, (2006) 1533-1537, https://doi.org/10.1016/j.jpowsour.2005.10.013

5. P. Burgmayer, R.W. Murray, Faster ion gate membranes, J.Electroanal,chem.,147, (1983) 339-344, https://doi.org/10.1016/S0022-0728(83)80080-1

6. J.M. Sansinena, J. Gao, H.L. Wang, High-performance, Monolithic polyaniline Electrochemical Actuators, Advanced Functional Materials, 13, 9, (2003) 703-709, https://doi.org/10.1002/adfm.200304347

7. S.T. Doslu, B.D. Mert, B. Yazici, Polyindole top coat on $\mathrm{TiO}_{2}$ sol-gel films for corrosion protection of steel. Corrosion Sciene colume 66, 51-58 (2013). https://doi.org/10.1016/j.corsci.2012.08.067

8. LuO.M. Chan Qi, P. Hemmershoj, D. Zhou, Y. Han, B. Laursen, C.G. Yan, B. Han, Micro porous polycarbazole with high specific surface area for gas storage and separation. J.Am.Chem.Soc 134, 6084-6087 (2012). https://doi.org/10.1021/ja300438w

9. T. Ahmad Zahoor, J. Qiu, Zhang, Synthesis and characterization of Ag@polycarbazole nanopaticles and their novel optical behavior. J.Mater Sci 44, 6054-6059 (2009). DOI 10.1007/s10853-009-3831-y

10. A. Umair Baig, Waseem, L. Wani, T. Hun, Facile synthesis of electrically conductive polycarbazolezirconium(IV)phosphate cation exchange nanocomposite and its room temperature ammonia sensing performance. New J, Chem 20, 1-27 (2015). DOI:10.1039/C5NJ01029B

11. P. Aditi Srivatava, Chakrabarti, Fabrication and electrical characterization of a polycarbazole/ZnO based Organic and inorganic hybride heterojunction diode. superlattices and Microstructures $\mathbf{8 8}$, 723-730 (2015). Doi:org/10.1016/j.spmi.2015.10.035 
12. L.N. Shubha, P. Madhusudana Rao, Temperature characterization of dielectric permittivity and AC conductivity of nano copper oxide- doped polyaniline composite, $6,3,(2016)$ 1650018-1650025, DOI:10.1142/S2010135X16500181

13. A.M. El Sayed, W.M. Morsi, $a-\mathrm{Fe}_{2} \mathrm{O}_{3}$ /(PVA + PEG) Nanocomposite films; synthesis, optical, and dielectric characterizations. J.Mater Sci 49, 5378-5387 (2014). DOI 10.1007/s10853-014-8245-9

14. Y. Jianghao, MinLi,H. Wang, X. Lian, Y.F.Z. Xie, B. Niu, Wenfeng Li, preparation and property studies of chitosan-PVA biodegradable antibacterial multiplayer films doped with $\mathrm{Cu}_{2} \mathrm{O}$ and nano-chitosan composites. Food control 126, 108049 (2021). Doi.org/10.1016/j.foodcont.2021.108049

15. J. Zhang, D. Shu, T. Zhang, H. Chen, H. Zhao, Y. Wang, Z. Sun, Shaoqing,Tang, Xueming Fang, Xi Ufang Cao, Capacitive properties of PANI/MnO2 synthesized via simultaneous-oxidation route. Jouranal of Alloys and Compounds 532, 1-9 (2021). Doi.org/10.1016/j.jallcom.2012.04.006

16. A. De, A. Das, S. Lahiri, Heavy ion irradiation on conducting polypyrrole and $\mathrm{ZrO}_{2}$-polypyrrole nanocomposites. Synth. Met. 144(3), 303-307 (2004). Doi.org/10.1016/j.synthmet.2004.04.006

17. M.O. Ansari, F. Mohammad, Thermal stability, electrical conductivity and ammonia sensing studies on p-toluenesulfonic acid doped polyaniline:titanium dioxide(pTSA/Pani:TiO2) nanocomposites. Sens. Actuators B 157, 122-129 (2011). Doi.org/10.1016/j.snb.2011.03.036. 1

18. P. Manivel, S. Ramakrishnan, K. Nikhil, A. Kothukar.N. Balamurugan.Ponpandian, D.Mangalaraj, C..Viswanathan, Optical and electrochemical studies of polyaniline/SnO2 fibrous nanocomposites, Materials Research Bulletin, 48, 2, (2013) 640-645, doi.org/10.1016/j.materresbull.2012.11.033

19. S. Ashokan, P. Jayamurugan, V.Ponnuswamy, Effects of $\mathrm{CuO}$ and Oxidant on the Morphology and Conducting Properties of PANI:CuO Hybrid Nanocomposites for Humidity Sensor Application, Polymer Science, 2019,61,86-97

20. G. Rajasudha, L.M. Jayan, D. Durga Lakshmi, P. Thangadurai, Nikos -Boukos, V. Narayanan, A. Stephen, Polyindole-CuO composite polymer electrolyte containing $\mathrm{LiClo}_{4}$ for lithium ion polymer batteries, Polym. Bull. (2012) 68:181-196, DOI 10.1007/s00289-011-0548-1

21. M. Khan Malook, Ihsan-ul-Haque, Khan, Muhammed ali, Polypyrrole-Cuo based composites, promotional effects of $\mathrm{CuO}$ contents on polypyrrole characteristics. Journal of Material Science: Materials in Electronics 30, 3882-3888 (2019). Doi.org/10.1007/s10854-019-00673-x

22. R. Gangopadhyaya, A. De, S. Das, Transport properties of polypyrrole-ferric oxide condcucting nanocomposite. Jouranl of applied physics 87, 2363 (2000). https://doi.org/10.1063/1.372188

23. D. Rajasudha Ganesan, N. Dhinasekaran, Thangadurai, Paramasivam, Boukos, Narayanan Vengidusamy, and Stephen arumainathan, Preparation and Characterizaton of Polyindole-Iron Oxide composite Polymer Electrolyte Containing $\mathrm{LiClO}_{4}$. Polymer-Plastics Technology and Engineering 51, 225-230 (2012). doi.org/10.1080/03602559.2011.618159

24. N.C. Horti, M.D. kamatagi, N.R. Patil, S.K. Nataraj, S.A. Patil, S.R. Inamdar, Synthesis and photoluminescence properties of polycarbazole/tin oxide $\left(\mathrm{PCz} / \mathrm{SnO}_{2}\right)$ polymer nanocomposites. Polym. Bull. (2020). https://doi.org/10.1007/s00289-020-03428-5 
25. S. Madhurima Das, Roy, Preparation, characterization and Properties of Newly Synthesized $\mathrm{SnO}_{2}-$ Polycarbazole Nanocomposite via Room Temperature solution phase synthesis Process, Materials Today: Proceedings, 18, (2019) 5438-5446, https://doi.org/10.1016/j.matpr.2019.07.573

26. V. Raj, D. Madeswari, M. Mubarak Ali, Journal of applied science, Chemical Formation, Characterization and Properties of Polycarbazole, 116, 147-154 (2010), https://doi.org/10.1002/app.31511

27. A. Kumar, M. Tiwari, R. Prakash, Electrochemical Study of Interfacially Synthesized Polycarbazole with Different Oxidants, ChemElectroChem, 2, (2015) 2001 - 2010 DOI: 10.1002/celc.201500318

28. M.A. Muhammaad Aslam, Z.A. Kalyar, Raza, Fabrication of nano-CuO-loaded PVA composite films with enhanced optomechanical properties, Polymer Bulletin, https://doi.org/10.1007/s00289-02003173-9

29. J. Selvi, S. Mahalakshmi, V. Parthasarathy, Y.-F. Vhechia Hu, K.-L. Lin, R. Tung, A.A. Anbarasan, Annie, Optical, Thermal, Mechanical Porperties, and Non-Isothermal Degradation Kinetic Studies on PVA/CuO Nanocomposites, 40, 9, (2019) 3737-3748, https://doi.org/10.1002/pc.25235

30. M.S. Mohammad Shakir, Noor-e-Iram, S.I. Khan, A.A. Al-Resayes, Khan, U. Baig, E. Conductivity, Isothermal Stability, and Ammonia-Sensing Performance of Newly Synthesized and Characterized Organic-Inorganic Polycarbazole-Titanium Dioxide Nanocomposite. Ind. Eng. Chem. Res. 53, 8035-8044 (2014). dx.doi.org/10.1021/ie404314q

31. P. Syed Abthagir, R. Saraswathi, Charge transport and thermal properties of polyindole, polycarbazole and their derivatives, Thermochimica Acta, 424, 25-35 (2004), Doi.10.1016/j.tca.2004.04.028

\section{Figures}



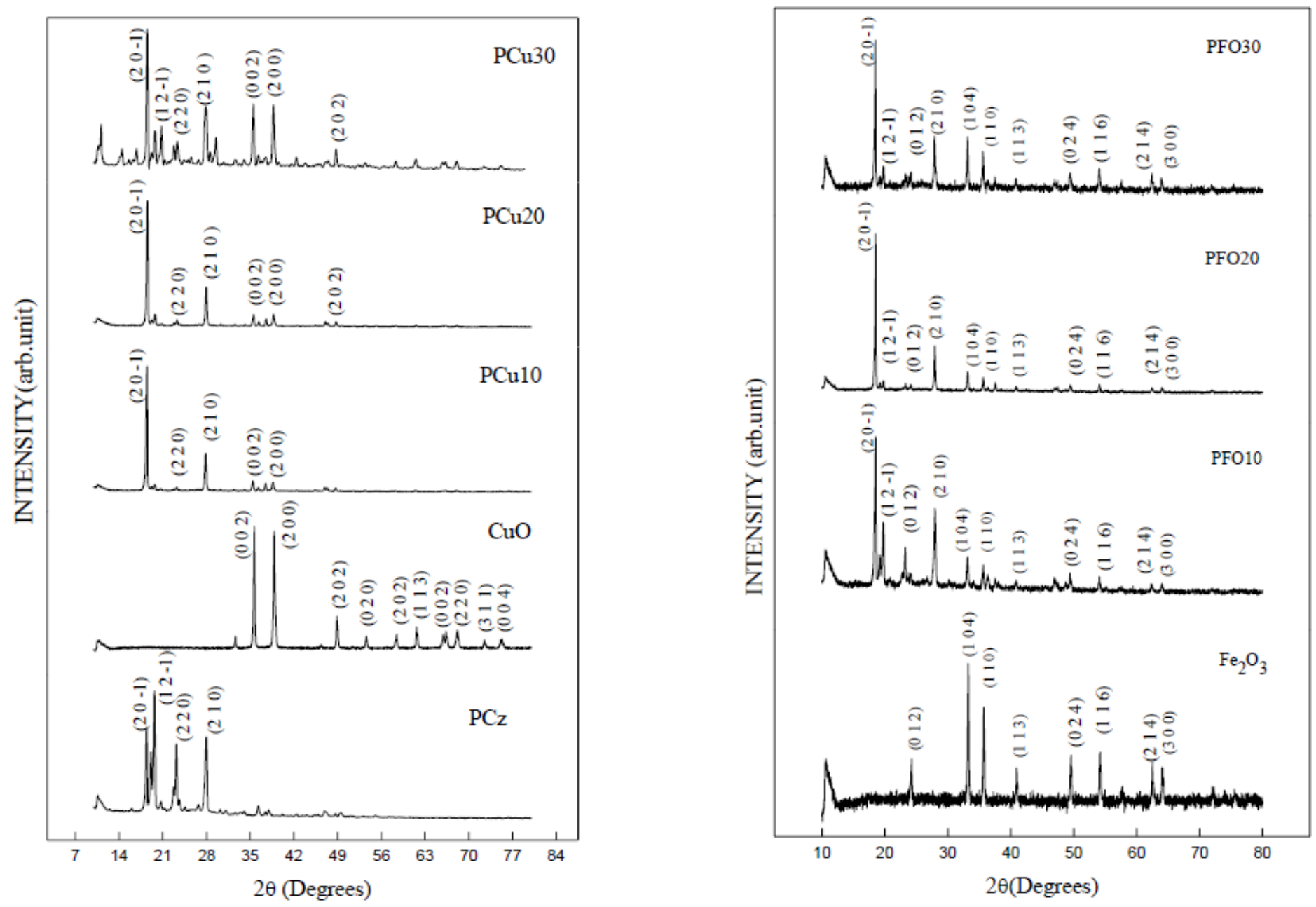

Figure 1

XRD pattern of CuO, Fe2O3, PCz, PCuO and PFO nanocomposites. 

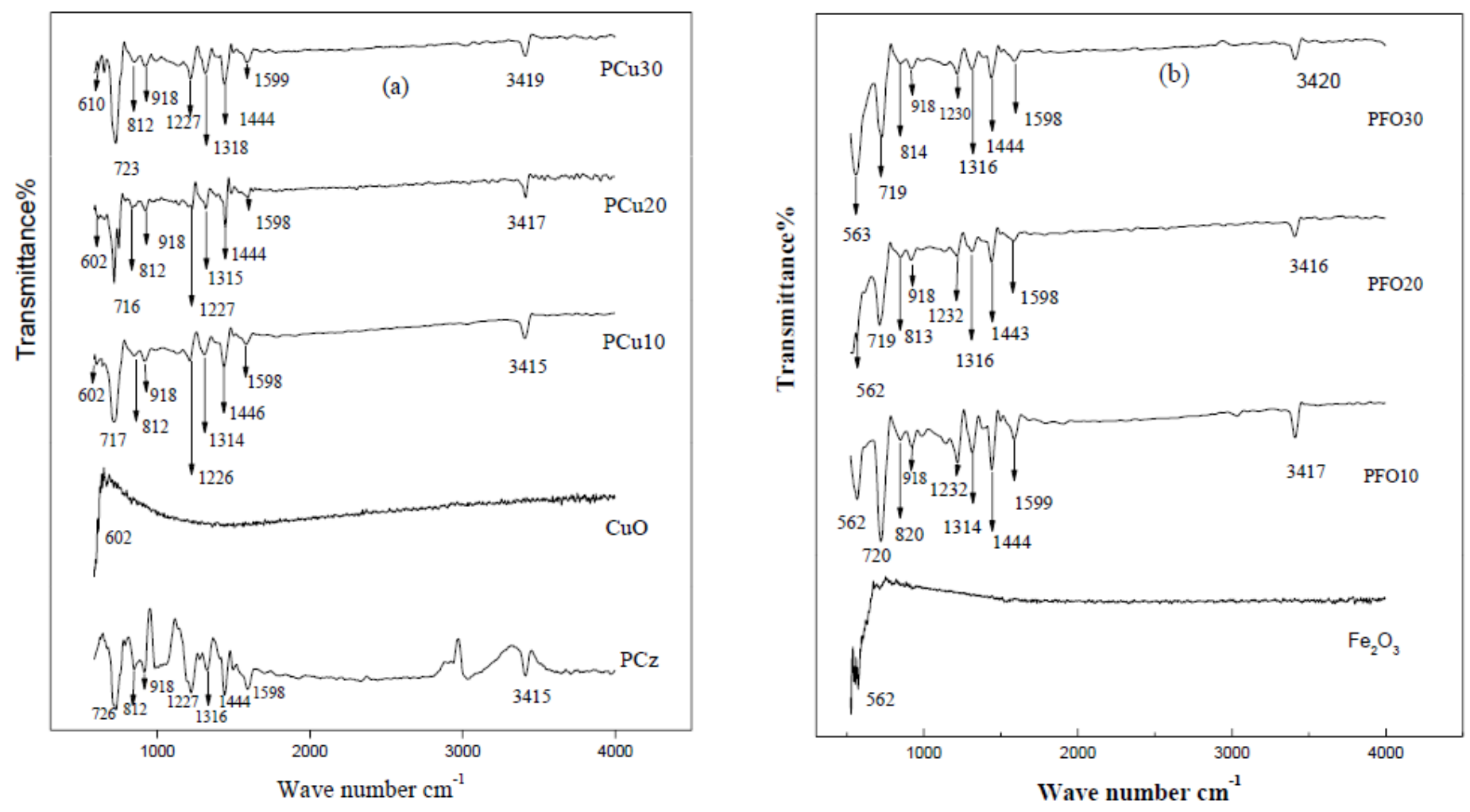

Figure 2

FTIR spectra of (a) PCz, CuO and, PCuo and, (b) Fe2O3 and PFO composites
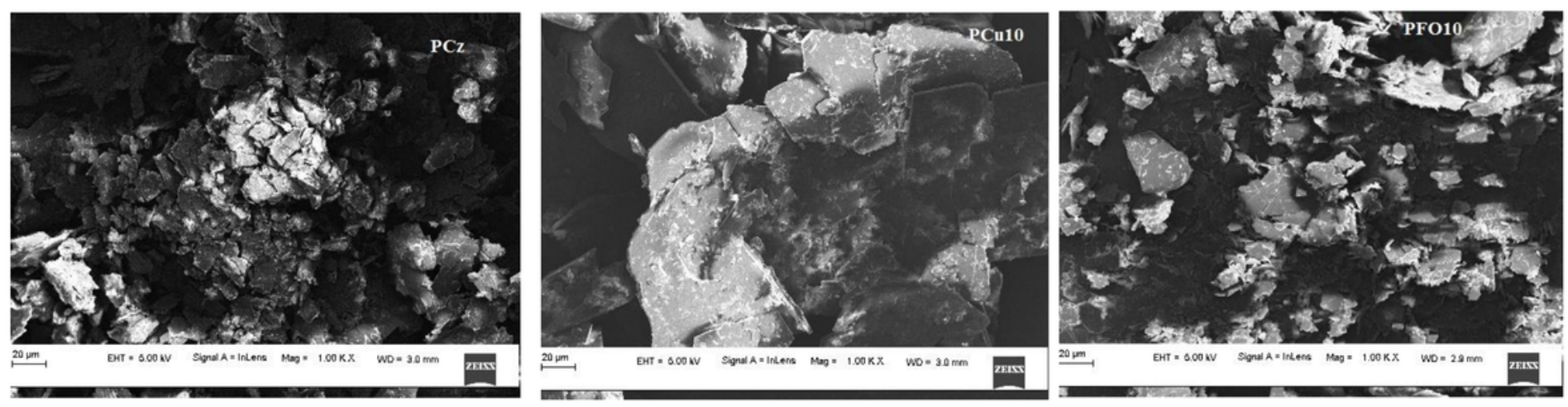

Figure 3

SEM morphologies of PCz, PCu10 and PF010 

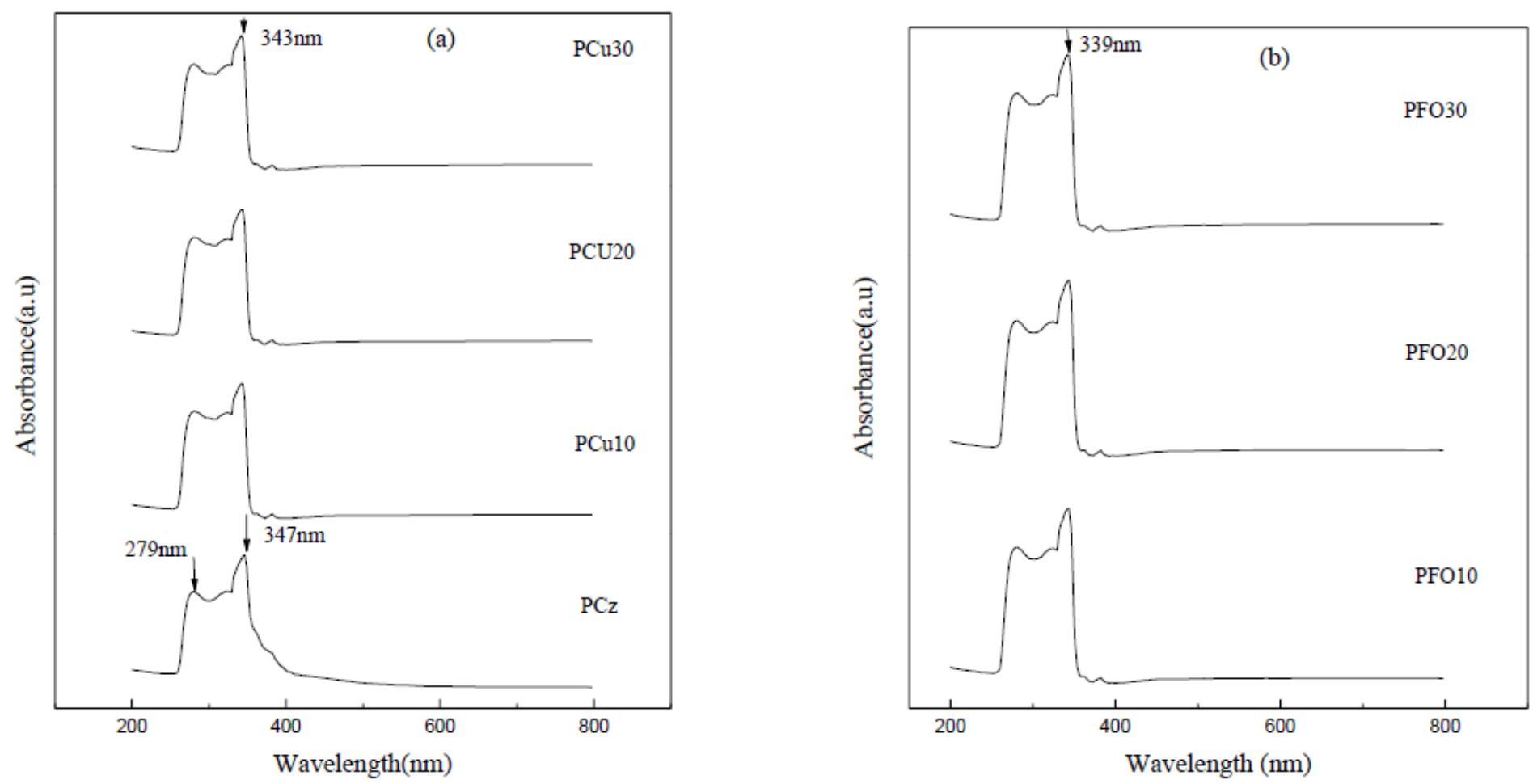

Figure 4

Optical absorbance versus wavelength for $\mathrm{PCz}$ and (a) PCz/CuO and (b) PCz/Fe2O3 composites
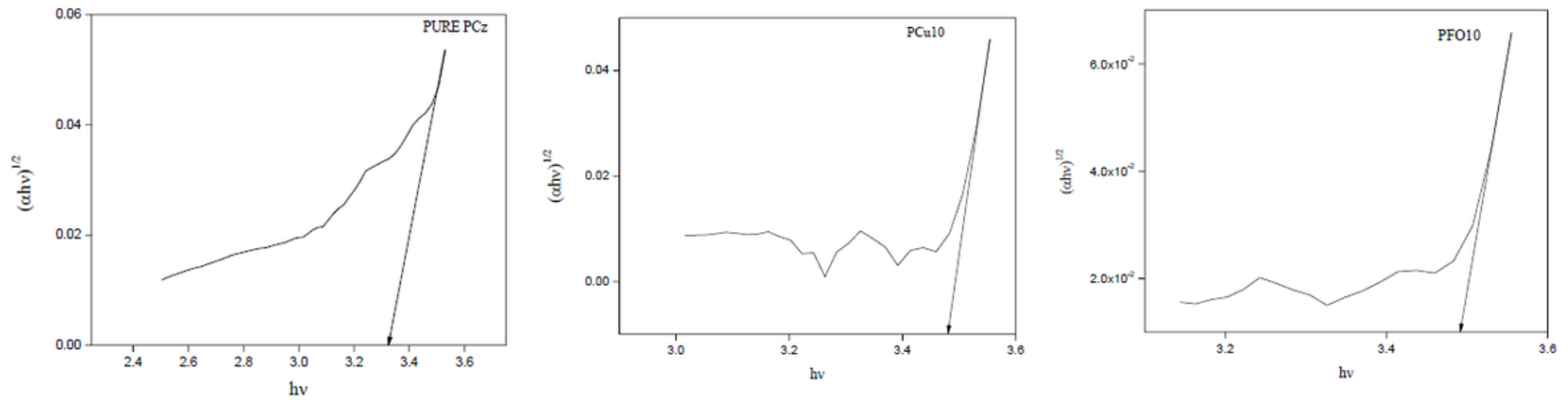

Figure 5

Tauc's plots of (ahv) $1 / 2$ versus hv for direct band gap determination.
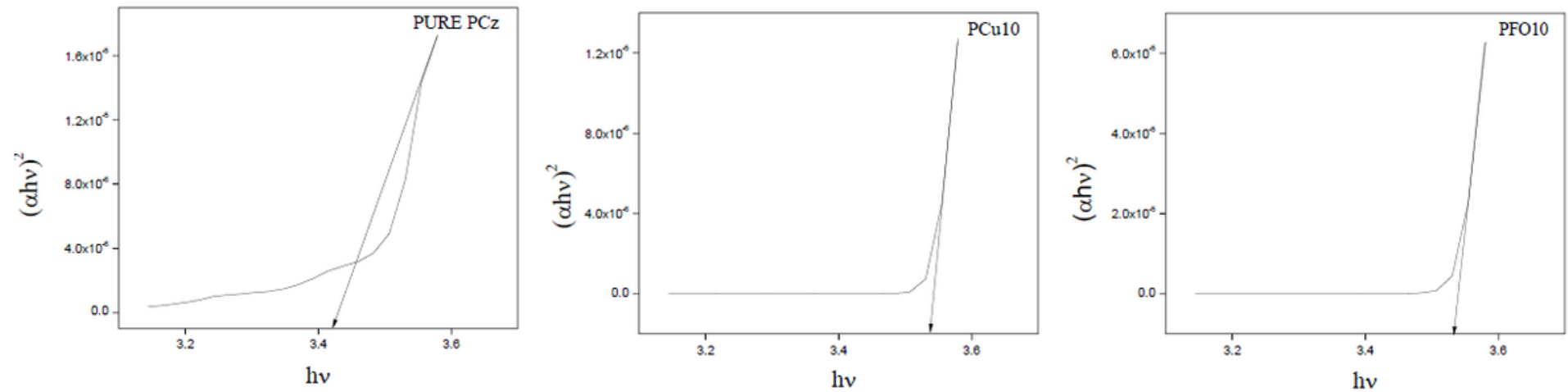

Page $15 / 18$ 
Figure 6

Tauc's plots of (ahv)2 versus hv for indirect band gap determination
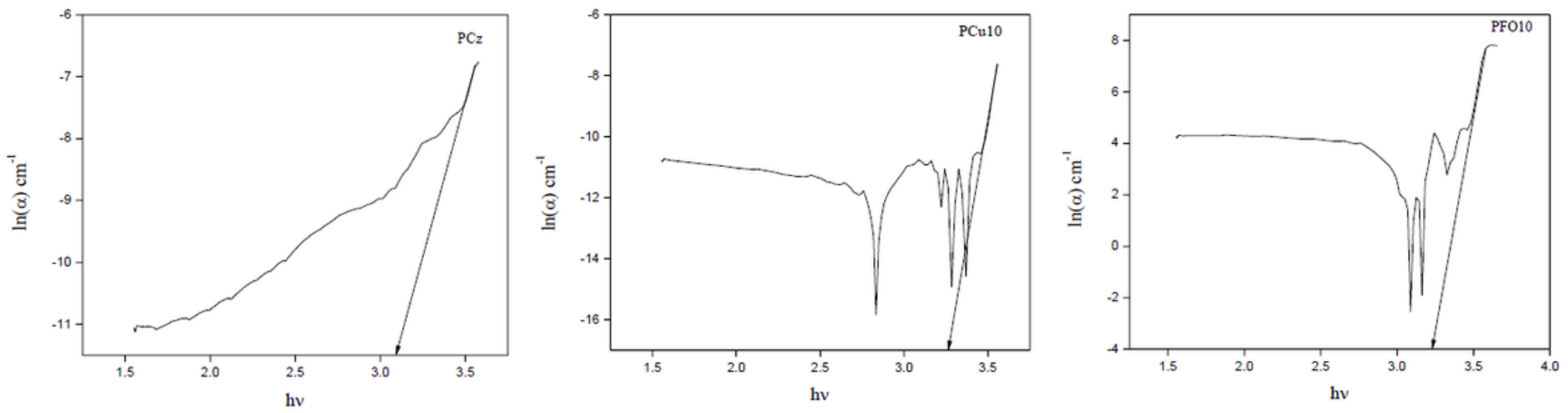

Figure 7

Plots of $\ln (\mathrm{a})$ versus hv for PCz, PCu10 and PFO10 composites for Urbach energy determination.

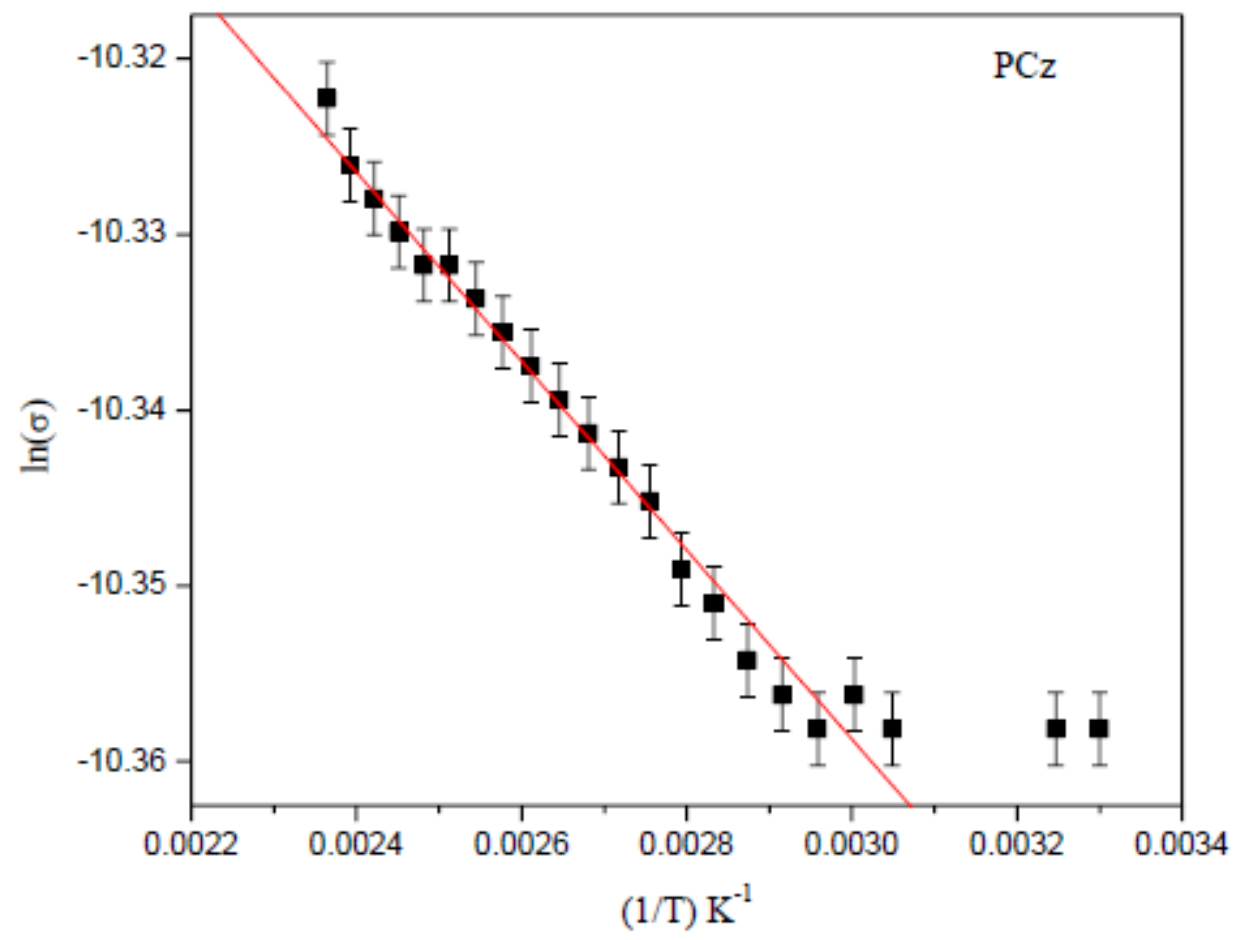

Figure 8

Plot of $(\operatorname{In}(\sigma)$ versus $1 / T)$ for PCz. Solid line is a linear fit to the data at high temperature. 

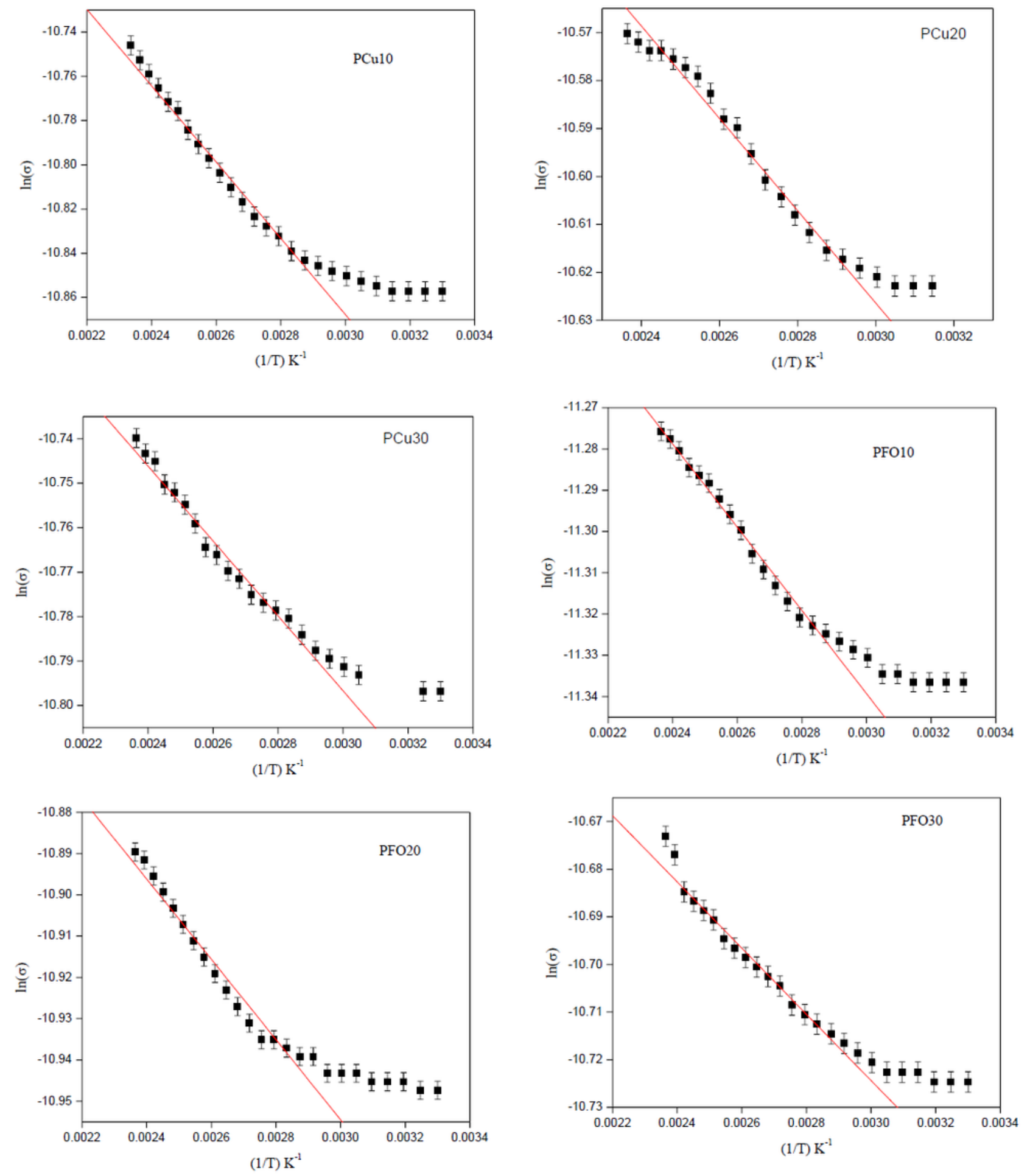

\section{Figure 9}

Plots of $\ln (\sigma)$ versus $(1 / \mathrm{T})$ for PCuO and PFO composites. Solid lines are the linear fits to data at high temperature. 

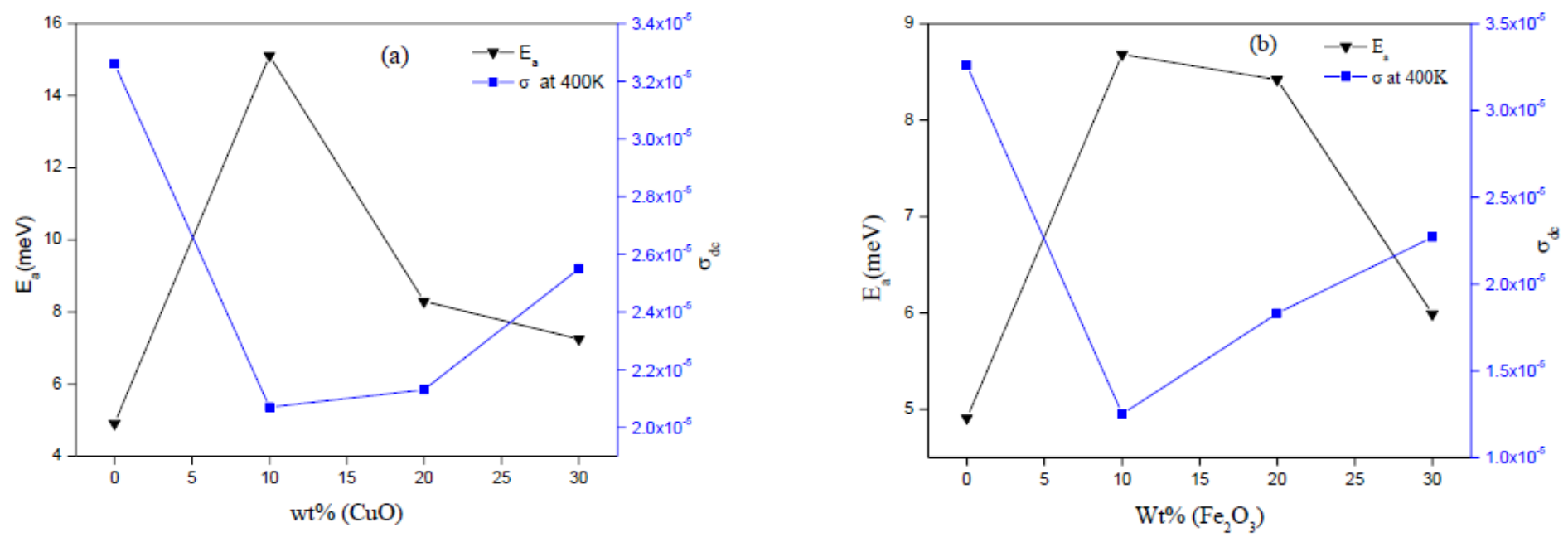

Figure 10

Plots of Ea and $\sigma(400 \mathrm{~K})$ versus (a) wt\% of $\mathrm{CuO}$ and (b) wt\% of $\mathrm{Fe} 2 \mathrm{O} 3$ in their respective composites. 